\title{
The Effect of a Garden-Based Nutrition Education Program on the Consumption of Fruits and Vegetables by Hispanic Children
}

\author{
Megan Somerville, Lisa A. Kessler, Sharonda P. Wallace, Bonny Burns-Whitmore \\ California State Polytechnic University, Pomona
}

\begin{abstract}
Objective: A garden-based nutrition education program was developed to increase the fruit and vegetable intake among 6-to-12-year old children in an after-school setting in southern California. It was hypothesized that the intervention would increase intake and preference for fruits and vegetables.

Methods: A 4-month curriculum using social cognitive theory was developed for participants at a Boys and Girls Club. A pre and post-test validated survey assessed measured fruit and vegetable intake and participants' height and weight were measured to calculate BMI. We pilot tested an observational method of assessing snack preference.

Results: Forty participants completed the study, $83 \%$ of which were Hispanic. Significant results were found in fruit and vegetable servings consumed daily $(\mathrm{p}<0.05)$. Self-reported scores for daily fruit servings increased from $2.23 \pm 4.18$ to $4.13 \pm 2.16$. Self-reported scores for daily vegetable servings increased from $2.17 \pm 1.82$ to $3.07 \pm 1.87$. Upward trends were shown in fruit and vegetable snack preference.

Conclusions and Implications: No other garden-based nutrition education interventions have targeted primarily Hispanic youth in an extramural setting. Continued research using SCT curricula and quantitative measurements is warranted.

(C) 2012 Californian Journal of Health Promotion. All rights reserved.

Keywords: nutrition, school-aged children, after-school programs, fruits and vegetables, social cognitive theory
\end{abstract}

\section{Introduction}

Children in the United States are consuming far less than the recommended amounts of fruits and vegetables per day (Casagrande, Wang, Anderson \& Gary, 2007). Less than $10 \%$ of all youth nationwide (Guenther, Dodd, Reedy \& Krebs-Smith, 2006) actually eat four to five daily servings of fruits and vegetables. Hispanic children in the United States are reported to have less frequent consumption of fruits and vegetables than the majority of their nonHispanic peers (Dave, Evans, Saunders, Watkins \& Pfieffer, 2009). The only two published studies found revealed that Mexican-American children consume an average of 1.55 daily servings of fruits and vegetables combined, compared to Caucasian youth who intake an average of 3.6 servings per day (Murphy, Castillo, Martorell \& Mendoza, 1990;
CDCP/NCHS, 2001-2002). Dave, et al in 2009, found that for Hispanic children low fruit and vegetable intake was associated with higher levels of acculturation and higher rates of food insecurity (Dave, Evans, Saunders, Watkins \& Pfieffer, 2009). A 1994 study found that those Hispanic children who were eating the least fruits and vegetables (lowest quintile of consumption compared to other Hispanic children), were consuming more fruit punch and soda then other children (Basch, Zybert \& Shea, 1994). A 2007 study found a difference in Hispanic children's intake by grade level with those children in 8th and 11th grade consuming a higher amount of high fat meats, sweet rolls, French fries and soda compared with Hispanic children in 4th grade. A consistently low consumption of fruit and vegetables among adults is positively associated with obesity, cardiovascular disease, diabetes and cancer 
(USDHHS, 2010). Since Hispanics are currently the fastest growing demographic population in the United States (USCB, 2010), their nutritional behaviors and increased risk for obesity-related conditions is of great concern. Nutrition interventions that specifically target Hispanic populations are imperative to improving fruit and vegetable consumption and subsequent overall health in this growing population (Heim, Stang \& Ireland, 2009).

Garden-based nutrition education programs have recently emerged as a method of modifying children's eating behaviors and have shown success in improving fruit and vegetable intake (Heim, Stang \& Ireland, 2009). The predominant basis for nutrition and gardening curriculum development has been social cognitive theory (SCT), which is based on the inclusion of multiple interactive intervention components in order to influence behavior change. Previous studies have incorporated hands-on activities with various types of produce to promote a simultaneous increase in knowledge, exposure, consumption and overall preference for fruits and vegetables. While previous results have been promising, the various health and cultural requirements of individual ethnic groups create a need to test the effectiveness of similar interventions on more specified target groups.

The purpose of this project was to develop, implement and evaluate a garden-based nutrition education program that would improve the fruit and vegetable snack eating behaviors of participating Hispanic children. We predicted that weekly participation would increase both self-reported and observed fruit and vegetable consumption.

\section{Methods}

The curricula and goals of this project were approved by the director of the Boys and Girls Club of Pomona, California, and the project procedures and consent form were approved by the Institutional Review Board of California State Polytechnic University, Pomona.

\section{Participants}

Participants were recruited from members of the
Boys and Girls Club of Pomona who actively participated in the facility's existing gardening program. Consent forms were available in Spanish and English and were signed by both participants and their parents. A total of 40 children between the ages of 6 and 12 volunteered to participate. Their mean age was 9 years. The majority of participants were Hispanic (90\%), but those of other ethnicities were not excluded.

\section{Measures, Procedures, and Analyses}

Daily Fruit and Vegetable Intake.

A previously validated survey to assess selfreported fruit and vegetable intake was administered before and after the intervention (Sylva, Townsend, Martin \& Metz, 2010). The survey consisted of seven questions. Five questions were multiple choice regarding daily fruit and vegetable eating behaviors. Available answers to these questions were "no," "yes, sometimes," "yes, often," and "yes, everyday." The remaining two questions asked participants to write how many servings of fruit and vegetables they ate each day. Participants were seated together, as each question was read aloud and serving sizes were described. Participants were instructed to answer each question regarding daily fruit and vegetable intake to the best of their ability and were allowed to ask questions for clarification throughout the process.

\section{Snack Preference.}

An observational measurement of snack intake was pilot tested to quantitatively measure the children's preference for fruits and vegetables versus traditional snack options. Observation of children's eating is often used to observe school meals (Baglio, Baxter, Guinn, Thompson, Shaffer \& Frye, 2004), but has not been used to observe snacking behavior to measure the effectiveness of an intervention. An observational method appears to have less bias and may be a good addition to the use of traditional child recall methods which have shown to have drawbacks (Baglio, Baxter; Guinn, Thompson, Shaffer \& Frye, 2004). The authors could find only one published article on observing children's snack behavior in a natural setting (O'Brien, Walley, Anderson-Smith \& 
Drabman, 2002). In the referenced study, adolescent children were observed in their snack purchases at a movie theater. Data included the number of snacks and sodas purchased as well as the caloric intake of these items. The current study, on the other hand, did not involve a monetary component, as snacks were free for participants.

In this pilot method, participants were given the opportunity to take snacks provided on individual plates in a recreation room. Two plate options were provided: a fruit and vegetable plate and an alternate plate. In order to abide by USDA snacking guidelines (USDA, 2010), each plate represented one serving and participants were allowed to choose two plates each, so that their snack consisted of a total of two servings (approximately 1.5 ounces) of food. The fruit and vegetable plate consisted of orange slices and cucumber slices. Tortilla chips were chosen as the alternate snack option based on their popularity in our target population and their high national incidence of consumption by children ages six to eleven (Sadeghi \& Marquart, 2009). Unlike the previously referenced study, the current pilot method observed actual amount of snacks consumed as well the amount taken. Participants were instructed to stay in the recreation room during consumption and to throw waste into a designated bin. Partially eaten snack items were counted as completely wasted and were considered part of the total waste in order to eliminate fractional results. Total waste of each snack item was subtracted from total amount taken to calculate the total number of servings consumed for each type of snack across the sample. With this information we were able to calculate the average number of servings consumed for each type of snack among the sample (with a possible range of 0-2).

We used paired samples t-tests to compare pretest and post-test scores on total scores for the fruit/vegetable consumption survey items. Due to the small sample size, we did not statistically adjust for any demographic covariates. Individual-level data was not collected for snack selection. Hence, it was not possible to conduct standard deviations for the average number of fruit/vegetable servings consumed and tortilla chips consumed. Nevertheless we presented the means at pretest and posttest for each of these snack preferences.

\section{The Intervention}

The intervention consisted of a weekly one-hour session, for 13 weeks. The students engaged in a variety of different activities each week, most of them emphasizing fruit and vegetable snack preparation. Some snack preparation activities included fruit kabobs, veggie wraps, fruit nachos and green smoothies. Other hands-on activities included blind taste testing, apple stamping, Produce Pictionary and Fruit and Veggie BINGO.

A variety of fruits and vegetables were available each week and participants often brought their own harvests from the gardening program. After demonstration of snack preparations, participants were encouraged to prepare and consume their own snacks during the session, as well as later in the week at home in order to validate their ability to work with both new and familiar fruits and vegetables. Participants also made snacks for both staff and family members, allowing them to demonstrate their acquired skills and knowledge to others.

\section{Results}

Significant results were found in the number of self-reported fruit and vegetable servings consumed daily $(\mathrm{p}<0.05)$. Scores reporting the number of daily fruit servings increased from $2.23 \pm 4.18$ to $4.13 \pm 2.16$. Scores reporting the number of daily vegetable servings increased from $2.17 \pm 1.82$ to $3.07 \pm 1.87$.

Figure 1 shows the average number of servings consumed of each type of snack before and after the intervention, with a range of 0-2. The difference between maximum possible snack consumption ( 2 servings) and the actual amount consumed of each snack reflects total plate waste. Average number of fruit and vegetable servings increased from 0.68 servings to 1.28 servings. Average number of chip servings decreased from 0.94 servings to 0.30 servings. 
Figure 1

Average Snack Consumption

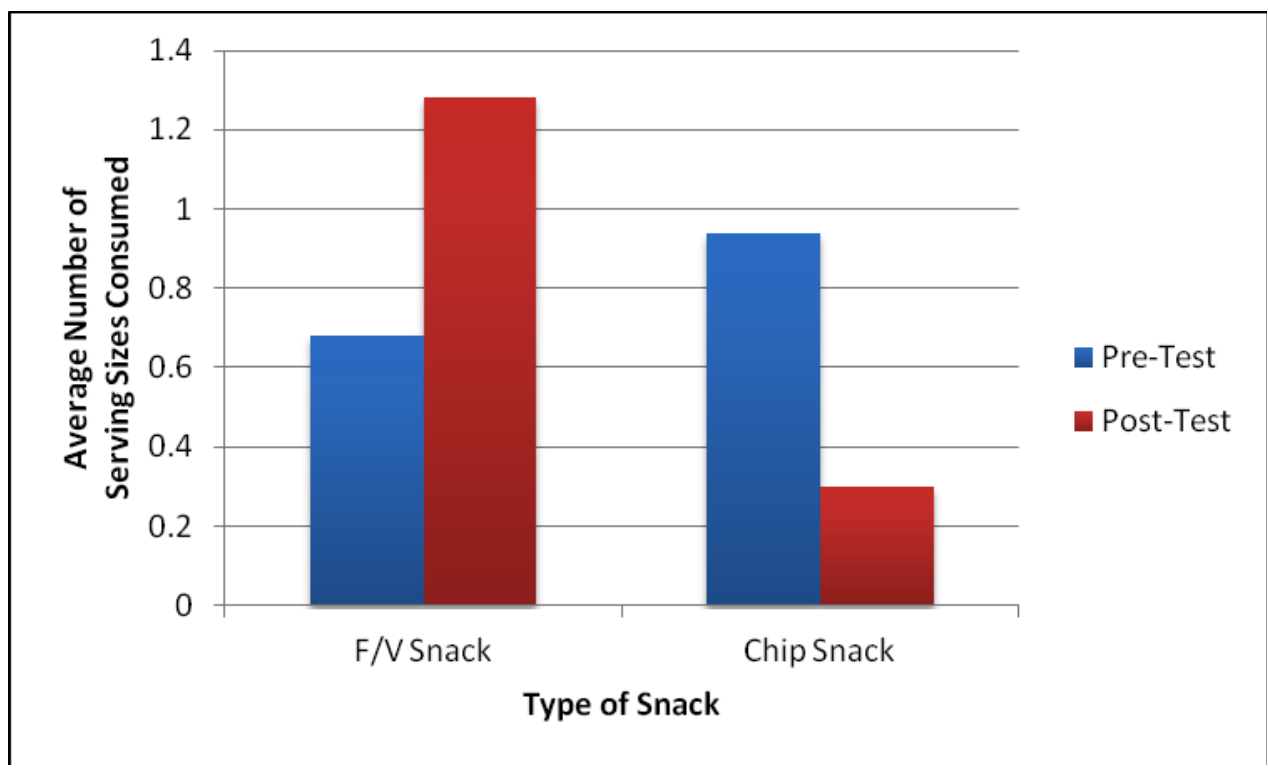

Figure 1. Average number of servings consumed before and after intervention for each type of snack among the sample $(\mathrm{n}=30)$. F/V refers to fruit and vegetable snack option, which included both oranges and cucmbers.

These results reflect an overall upward trend in preference for fruit and vegetable snacks and a downward trend in preference for chip snacks.

\section{Lessons Learned}

This study showed an increase in children's intake of fruits and vegetables based on both self-reports and observation methods. We also observed an increase of children's preference for healthier snacks, in addition to a reduction in plate waste of healthier items. One likely reason for this positive behavior change is the highly interactive nature of each session. Our results are similar to the garden-based study by Heim, Stang and Ireland, in which the improvements shown in fruit and vegetable eating behaviors were strongly associated with the "experiential learning" environment of each lesson (Heim, Stang \& Ireland, 2009). Participants in our study learned new uses for a variety of fruits and vegetables through the use of hands-on activities and were given the opportunity to demonstrate their new knowledge and skills to both their peers and family members. Such interaction not only stimulated an increased interest in fruits and vegetables, but also prompted continuing dialogue concerning produce in multiple settings. The children appeared genuinely enthusiastic throughout the course of the intervention and 30 of the initial 40 participants attended most sessions.

Another contributor to the results of this intervention may have been the familiarity of both the venue and many of the discussions. Traditional Hispanic foods were often used to prompt participants to consider ways of adding fruits and vegetables to these dishes. The Boys and Girls Club was an appropriate venue as it was a comfortable environment for participants, which allowed for rapid acceptance of the nutrition program. It was also an excellent site to reach this target population and it allowed for autonomy of curriculum development and implementation.

The pilot method of snack preference allowed for a quantitative evaluation of this education 
intervention. The standardization of snack serving sizes along with the inclusion of plate waste created a numerical illustration of the voluntary snack selections of children before and after an interactive nutrition program. This method also eliminated the response bias inherent in self-reported questionnaires. Similar preference methods would be appropriate in future interventions and would be even more valid with a greater amount of snack options and a larger population.

While findings from this study are encouraging, there were several limitations of an out-of- school intervention. For instance, the limited capabilities of the site kitchen and the availability of other concurrently ongoing activities for the children sometimes caused lesson limitations, variable attendance and multiple distractions. Despite these barriers, this interactive, SCT-based after school gardening curriculum for Hispanic children did appear to have a positive effect on the snacks chosen by participants and should be further studied as a potentially effective way to improve the diet of Hispanic youth. Future studies should utilize a control group in order to compare the relative effectiveness of the intervention.

\section{References}

Baglio, M. L., Baxter, S.D., Guinn, C. H., Thompson, W. O., Shaffer, N. M, \& Frye, F. H. (2004). Assessment of interobserver reliability in nutrition studies that use direct observation of school meals. Journal of American Dietetic Association, 104, 1385-1392.

Basch, C. E., Zybert, P., \& Shea, S. (1994). 5-A-Day: Dietary Behavior and the Fruit and Vegetable Intake of Latino Children. American Journal of Public Health, 84, 814-818.

Casagrande, S. S., Wang, Y., Anderson, C., \& Gary, T. L. (2007). Have Americans Increased Their Fruit and Vegetable Intake? The Trends Between 1988 and 2002. American Journal of Preventative Medicine, 32, 257-263.

Centers for Disease Control and Prevention, National Center for Health Statistics. NHANES 2001-2002. Available at: http://www.cdc.gov. Accessed May 15, 2010.

Dave, J. M., Evans, A. E., Saunders, R. P., Watkins, K. W., \& Pfeiffer, K. A. (2009). Associations among Food Insecurity, Acculturation, Demographic Factors, and Fruit and Vegetable Intake at Home in Hispanic Children. Journal of American Dietetic Association, 109, 697-701.

Guenther, P., Dodd, K. W., Reedy, J., \& Krebs-Smith, S. M. (2006). Most Americans eat much less than recommended amounts of fruits and vegetables. Journal of American Dietetic Association, 106, 1371-1379.

Heim, S., Stang, J., \& Ireland, M. (2009). A Garden Pilot Project Enhances Fruit and Vegetable Consumption among Children. Journal of American Dietetic Association, 109, 1220-1226.

Murphy, S. P., Castillo, R. O., Martorell, R.,\& Mendoza, F. S. (1990). An Evaluation of food group intakes by Mexican-American children. Journal of American Dietetic Association, 90, 388-393.

O'Brien, T.P., Walley, P.B., Anderson-Smith, S., \& Drabman, R.S. Naturalistic observation of the snackselecting behavior of obese and nonobese children. Addictive Behaviors 2002. Available at: http://dx.doi.org/10.1016/0306-4603(82)90028-4. Accessed July 28, 2012.

Sadeghi, L., \& Marquart, L. (2009). Whole grain snack intake in an after-school snack program: a pilot study. Journal of Foodservice, 20, 71-80.

United States Census Bureau. Hispanic Population in the United States: 1970-2050. Available at: http://www.census.gov. Accessed May 15, 2010.

United States Department of Agriculture. Serving Sizes and School-Age Children: Gather the Portion Size Facts. Available at: http://www.schoolmeals.usda.gov. Accessed December 12, 2010.

United States Department of Health and Human Services. Healthy People 2010: National Health Promotion and Disease Prevention Objectives. Available at: http://www.healthypeople.gov. Accessed May 16, 2010. 
Sommerville, M., Kessler, L. A., Wallace, S. P., \& Burns-Whitmore, B. / Californian Journal of Health Promotion 2012, Volume 10, Special Issue: Obesity Prevention and Intervention, 20-25

Author Information

Megan Somerville, MS, RD,

California State Polytechnic University, Pomona,

Department of Human Nutrition and Food Science

*Lisa A. Kessler, DrPH, RD

California State Polytechnic University, Pomona

Department of Human Nutrition and Food Science $3801 \mathrm{~W}$. Temple Ave.

Pomona, CA 91768

909-869-2168

909-869-5078 (fax)

lakessler@csupomona.edu

Sharonda P. Wallace, PhD, RD

California State Polytechnic University, Pomona

Department of Human Nutrition and Food Science

Bonny Burns-Whitmore, DrPH, RD

California State Polytechnic University, Pomona

Department of Human Nutrition and Food Science

* corresponding author 